\title{
A spatially-resolved inventory analysis of the water consumed by the coal-to-gas transition of Pennsylvania
}

\author{
Sarah M. Jordaana, ${ }^{a, b}$
}

${ }^{a}$ School of Advanced International Studies, Johns Hopkins University, 1619 Massachusetts Ave NW, Washington, DC 20036, USA (Present Address); and,

${ }^{\mathrm{b}}$ Department of Political Science, University of Calgary, 2500 University Drive N.W., Calgary, AB, Canada T2N 1 N4.

\section{Lauren A. Patterson ${ }^{\mathrm{c}}$}

${ }^{c}$ Nicholas Institute for Environmental Policy Solutions, Duke University, 2117 Campus Drive Durham, NC 27708, USA.

\section{Laura Diaz Anadon ${ }^{\mathrm{d}, \mathrm{e}}$}

${ }^{\mathrm{d}}$ Department of Land Economy, University of Cambridge, Cambridge, CB3 9EP, UK (Present Address); and,

${ }^{\mathrm{e}}$ Belfer Center for Science and International Affairs, Harvard Kennedy School, Harvard University, 79 John F. Kennedy Street, Cambridge, MA 02138, USA.

* Corresponding author email address: sarahjordaan@jhu.edu. 
Abstract. Life cycle assessments (LCA) typically exclude spatial information in estimating the water consumption associated with a product, resulting in calls to improve regional detail to better reflect spatial variation. In response to these calls, we have compiled a spatially-resolved inventory of changes in water consumption associated with the coal-to-gas transition in Pennsylvania at the resolution of watersheds from 2009 to 2012. Results indicate that the total water consumption of the fuel extraction and power sectors in Pennsylvania increased by 7.6 million $\mathrm{m}^{3}$ (2 Bgal) over four years. At the state and watershed scales, we compare total water consumption for the coal-to-gas transition to a case where only the water consumed across two life cycle stages of electricity generation is considered - fuel extraction and use at the power plant to generate electricity. The results for the latter indicate that water consumption decreased by over 15.1 million $\mathrm{m}^{3}$ (4 Bgal). For both cases, watershed-level results showed water consumption generally increased in watersheds with growing shale gas activity or new natural gas capacity, while it decreased with diminishing coal-fired generation. Watershed-scale water consumption from 2009-2012 may be reversed from a net increase to decrease (and vice versa) when the total water consumption is compared to the water consumed specifically for life cycle stages of electricity generation, reinforcing the importance of further developing spatiallyresolved inventories for LCA. Focusing on the water consumption associated with only electricity generation and its fuel use does not capture the full effects of fuel extracted for use in other sectors. We suggest that spatially-explicit inventories should be a critical component in the development of more comprehensive, spatial LCA methodology. Spatial differentiation in inventories is necessary to adequately characterize watershed-level impacts that can be normalized over a functional unit. The approach can be used as a complementary assessment to LCA that can inform policy-makers and investors about where energy developments may pose 
additional risks to water supply and availability.

Keywords: water use; life cycle assessment; spatial analysis; power generation; coal mining; shale gas.

\section{Word count of submission (including figure captions): 7197}

\section{Introduction}

The coal-to-gas transition in Pennsylvania has resulted in changing spatial patterns of water consumption from 2009-2012 [1]. Life cycle assessment (LCA) is a method for examining the environmental burdens associated with a particular product or process from materials extraction to waste disposal (cradle to grave) [2], where environmental burdens can include resource demands such as water use [3]. For such assessments, water use is categorized as either water consumption (water that is removed from a source and not returned), or water withdrawals (water diverted from a source regardless of whether it is later returned) (e.g. [4]). LCA is often used to evaluate differences in water consumption across energy technologies, but it does not capture the changing spatial patterns of water consumption [5-7]. The need to further develop dynamic, spatially-resolved LCA has been noted, particularly to better represent the spatial variation in product flows and the heterogeneous patterns of environmental impacts $[2,8]$. Spatial differentiation within LCA would enable a more comprehensive understanding of localized impacts, such as those that might occur from water consumption. 
LCA comprises of four iterative stages: (1) goal and scope definition, (2) inventory analysis, (3) impact assessment, and (4) interpretation [9]. During the goal and scope definition, the product or process in question is identified along with the objective of the study, the system boundaries of the LCA are delineated, and the functional unit is defined. The functional unit serves as a normalization factor for the environmental burden being assessed, providing a reference to which the system's inputs and outputs are related [9]. The inventory analysis involves data collection and analysis necessary to quantify relevant inputs and outputs of the product or process in question. The impact assessment involves an evaluation of the environmental significance of the impacts resulting from the inventory results. We suggest that to characterize the impacts from water consumption per functional unit, inventories must be spatially differentiated. With spatial disaggregation at the resolution of watersheds, different impacts associated with water consumption that are typically evaluated in LCA (e.g. water stress [10] or scarcity [11]) may be calculated such that spatial patterns of water consumption can be recognized. Once a watershedlevel impact assessment is complete, results may be normalized over a functional unit, creating a more concrete connection between spatial differentiation in the inventory analysis stage with the impact assessment stage of LCA.

While LCA results typically exclude spatial and temporal information [2], methods and data are evolving to better incorporate spatiotemporal factors $[4,5,12-15]$ with the increased use of tools such as Geographic Information Systems (GIS) $[1,4,12,15]$. Life cycle inventories are more commonly considering site-level differences; however, the estimated impacts remain spatiallyaggregate without the spatial differentiation of the site-level inputs $[16,17]$. While less critical for unconstrained environmental burdens such as the release of carbon dioxide, the inclusion of 
geographical variation is crucial when considering spatially bound resources and impacts [18], such as those related to water [19]. Unlike greenhouse gas emissions, surface water and the impacts of its consumption are spatially constrained to the watersheds from which the water is withdrawn. LCA research to date, however, has been criticized for putting less weight on the spatial differentiation of water consumption when compared to the potential impacts to ecosystems [20]. One regionalized LCA of electricity generation in the United States has shown that important differences exist between site-generic and regional methods, but only site-level power plants were evaluated to link the inventory analysis to the impact assessment [12]. Spatially differentiated analyses of water consumed by power generation alone are commencing to emerge [21-23]; however, LCAs that compare water consumption of coal- and natural gasfired power continue to remain spatially aggregated without geographic boundaries $[6,7]$ or at state [5, 24] and national scales [25]. Thus far, LCAs have yet to comprehensively include spatially-differentiated water consumption for electricity generation in the inventory analysis stage that includes the extraction of fuel consumed by power plant operations at ecologicallyrelevant scales $[5,6,26]$.

To contribute to the development of spatially explicit LCA methodology for water consumption, we focus specifically on developing a spatially-resolved inventory of the water consumed by fuel extraction and power generation in the state of Pennsylvania at the scale of watersheds. While the scale of watersheds has been noted as a logical choice for LCA [15], inventory analyses have not yet been developed at this spatial resolution in a way that can be used to uncover differences in consumption and impacts across regions [19]. For example, Grubert et al. [5] considered how estimated ultimate recovery across shale gas basins may influence the water intensity of the fuel 
extraction stage of the life cycle of power generation; however, the life cycle results were neither spatially differentiated nor evaluated at ecologically-relevant scales such as watersheds. The inventory developed in this paper includes the monthly and annual water consumption for the coal-to-gas transition in Pennsylvania from 2009-2012 for each watershed (defined as HUC8 sub-basins - see Supplementary Material), providing a way in which spatial differentiation in inventories can contribute to the further development of assessments of the life cycle water consumption of products. Our contribution is two-fold. First, we develop an inventory as a step towards spatially-resolved LCA that complements present methodology with more detailed information about the spatial variability of water consumption. In particular, our watershed level assessment indicates that the coal-to-gas transition has had different impacts on water consumption across watersheds - a fact that is not yet well-captured within LCA methodology to date due to resource and data limitations. Estimates for water consumption by watershed can reverse or become less pronounced when the boundaries are limited to power generation and the fuel consumed in the state to generate electricity. Second, the inventories provide a useful accounting method for policy-makers and investors to better understand the changing spatial patterns of the water consumed by major technological transitions.

\subsection{The water implications of the coal-to-gas transition}

One of the key drivers of the coal-to-gas transition in the power sector of the United States [27] is the development and diffusion of shale gas extraction via hydraulic fracturing technologies. The coal-to-gas transition and its potential impact on water resources is prominent in areas of the United States where the role of natural gas for power generation has increased relative to coal, such as in Pennsylvania [1,27]. The national water consumption of shale gas extraction 
(estimated to be at most $31 \mathrm{Bgal} /$ year from 2012-2014 [28]) is small compared to that of power generation. Estimated water consumed for thermoelectric power generation in 2010 was 1,278 Bgal/year [28]. The related assessments of water consumed in the coal-to-gas transition have been limited in capturing spatially heterogeneous and temporally dynamic changes (e.g. Grubert et al. [5] recognized differences in shale gas basins but life cycle results remained spatially aggregate).

Important differences exist between site-specific, regional, and site-generic results for LCA of power generation $[1,12]$, pointing to the critical need to incorporate higher resolution spatial estimates of water consumption resulting from the deployment of new energy technologies to specific watersheds. LCAs of electricity generation that focus on water consumption have so far been insufficient in determining the actual impacts to watersheds from changes in how fuel is extracted and power is generated - they focus instead on comparisons across technologies $[5,6$, 24]. The limitation of present LCA methods traces back to the lack of spatial detail available in life cycle inventories [11]. Scholars have already noted that more detailed inventories will be required to account for the localized implications of water consumption within LCA [14].

Spatially-aggregate LCAs of electricity generation focus on the total water consumption per MWh with results showing that additional water consumed for hydraulic fracturing does not generally have a large impact on water consumption intensity for natural gas fired power in comparison to the most common cooling technologies (once-through and recirculating) $[7,29$, 30]. Yet, the extraction of shale gas results in increased water consumption compared to conventional gas extraction, with hydraulic fracturing being the primary differentiator $[6,7]$. 
Meldrum et al. [7], for example, reported a median water consumption for shale gas to be 16 gal/MWh compared to $4 \mathrm{gal} / \mathrm{MWh}$ for conventional gas - some estimates for the latter have been as low as zero [29]. Power generation was relatively large with median estimates of 100 gal/MWh for open loop cooling, $210 \mathrm{gal} / \mathrm{MWh}$ for cooling towers and 240gal/MWh for cooling ponds. These estimates do not account for acute changes in highly-localized water consumption particular to watersheds with changes in energy activity (e.g. increasing hydraulic fracturing). For example, water injected for each hydraulic fracturing event has been found to range from 7,600 to $49,000 \mathrm{~m}^{3}$ (2 to $13 \mathrm{Mgal}$ ) per well in watersheds in the Marcellus shale $[6,31,32]$. Conversely, studies that focus on fossil resource extraction alone do not consider the end use of the commodity (e.g. whether shale gas is used in power generation, home heating or exported from the state) $[32,33]$.

While the known magnitude of the power sector's water use may impact state-level policy and regulation [34-36], policy-makers and investors are actively making decisions related to fuel extraction and power generation at the more local, watershed scale. Meanwhile, the effects of expanding hydraulic fracturing for natural gas production at these smaller scales may increase water scarcity, particularly during summer or drought, resulting in limits to withdrawals [37]. The role of site-specific data in improving the accuracy of water consumption estimates has been recognized for LCA of power generation in Texas [5], but results have only been presented at the aggregated resolution of the state. The impact of water scarcity within regions becomes relevant when assessments of particular technological and industrial development are applied to relatively fine spatiotemporal resolutions (watersheds and months, for the case of this work). The selection of power plant technology, for instance, may be limited by the potential for water shortages if 
water supply is scarce and/or if water demand peaks are too high $[10,38]$.

\subsection{Study area}

Pennsylvania was selected as the study area in our analysis for two reasons: (1) the coal-to-gas transition is notable in both power generation and fuel extraction sectors [1], and (2) despite being known as a relatively water-rich state, restrictions have already been placed on shale gas operators at a time when water reductions were expected with changes in the power sector [1, 37]. The 2009-2012 (inclusive) time period of the present assessment captures the coal-to-gas transition in Pennsylvania when it was in full effect alongside the shale boom and when data for all sectors were available. The transition from coal to gas in the power sector is notable over this time period: electricity generated from coal in Pennsylvania fell from $48 \%$ to $39 \%$ of the total while electricity generated from natural gas grew from $13 \%$ to $24 \%$ [39]. Concurrently, unconventional gas production in the state grew from less than 0.1 trillion cubic feet (tcf) in 2009 to over 2 tcf in 2012 [40]. Although water is seemingly abundant in Pennsylvania, seasonal fluctuations in water availability combined with changing patterns of water consumption and withdrawals for different demands may result physical or regulatory limits to water availability. Intuitively, the coal-to-gas transition would be expected to result in a net reduction of water consumption if policy-makers rely on LCA results alone - replacing coal with natural gas as a power source results in at least a $40 \%$ reduction of water consumption for cooling per MWh of electricity generated [41]. Within a watershed, however, the cumulative effects of multiple shale gas wells consuming water from a small stream during the summer or during drought conditions could pose risk of water scarcity and adverse ecological impacts, even in Pennsylvania which is traditionally viewed as a water-rich state $[1,42]$. Water withdrawals were already suspended by 
the Susquehanna River Basin Commission (SRBC) due to dry conditions in both 2011 and 2012 [37]. To capture the influence of the coal-to-gas transition at scales more relevant to such decision-making, watersheds delineated by the United States Geological Survey's Watershed Boundary Dataset (WBD) Hydrological Unit Code 8 (HUC8) were used as the spatial unit of analysis in the present assessment. HUC8 watersheds are large enough to capture watershedlevel changes with the data that were available but small enough to illustrate the changing spatial patterns of inter-sectoral water consumption within Pennsylvania's watersheds (average size is $\left.3,100 \mathrm{~km}^{2}\right)$.

\section{Material and Methods}

\subsection{A spatially-resolved inventory of water consumed by the coal-to-gas transition}

A spatially explicit inventory is developed at the scale of watersheds (or HUC8 sub-basins, see Supplementary Material) to estimate the change in water consumption associated with of the coal-to-gas transition in the power sector of Pennsylvania from 2009 to 2012, including fuel extraction and thermoelectric power generation.

Water consumption for both fuel extraction and power generation was estimated for each site (power plant, well, and mine) to understand how water consumption patterns changed during the coal-to-gas transition. The inventory of fuel extraction includes coal mines and hydraulic fracturing while the assessment of the power sector includes to natural gas- and coal-fired power plants. No unified database exists for water consumption of the coal-to-gas transition in Pennsylvania at fine spatial and temporal resolutions $[32,43]$, so the necessary data were compiled for each site involved with fuel extraction and power generation for coal and natural 
gas.

Locations of 5,027 individual natural gas extraction sites that were drilled between 2009 and 2012 in Pennsylvania were compiled along with existing data on well-level water consumption [44-46]. Location and production data were compiled for 328 coal mines [47] and water consumption was estimated by multiplying mine production by the water intensity of coal mining and washing for each site $[29,48]$. Similarly, water consumption was determined by multiplying monthly generation $[49,50]$ by the water intensity of the plant type $[29,41]$ for each individual power plant that was reported to run on natural gas or coal in Pennsylvania (85 natural gas-fired power plants and 42 coal-fired power plants) $[49,50]$. Water consumption was then aggregated for all sites (natural gas wells, coal mines, and power plants) to the watershed-level at a monthly temporal resolution.

The difference in total water consumption between 2009 and 2012 was computed and mapped for all watersheds to represent the overall impact of the coal-to-gas transition on water consumption in Pennsylvania. Our assessment includes a comparison of the inventory of total water consumption (fuel extraction and power generation) to the inventory of end product water consumption across the two life cycle stages (where the fuel assessment is limited to what is used for electricity generation). Additional details on how water consumption was characterized at the site-level is provided in the Supplementary Material.

\subsection{System boundaries and watershed-level analysis}

Spatial boundaries, such as watersheds, are not the focus of LCA; rather, the system boundaries 
are typically defined by what is required to produce an end product (from cradle to grave) [51]. More specific to this analysis, the assessment of the fuel extraction stage would be limited to the natural gas and coal used for power generation, the latter being the end product. Data are not available, however, that describe the exact location of the fuel extracted that is consumed in electricity generation. This makes it challenging to precisely determine the location of the water consumption associated with the fuel consumed for power, even at the scale of watersheds. Without more comprehensive datasets linking fuel extraction to end use, the water consumption associated with electricity as a product in LCA (as opposed to the total consumption for the coal to gas transition) relies on spatial assumptions about the location of natural gas extracted for use in power generation - such assumptions are implicit to the typical site-generic LCA.

Two approaches to inventory analysis are developed have been developed to clarify the role of functional units in spatially-differentiated LCA. The first approach includes the total water consumption of the coal-to-gas transition, in which we assess all of the associated fossil fuel extraction and power generation for each watershed within the state of Pennsylvania. Watersheds may be considered the functional unit in this case. Second, the inventory is limited to include the water consumption across two life cycle stages of the end product of electricity generation (electricity generation and the fuel extracted in the state that is consumed for electricity generation). Pennsylvania data from 2009-2012 is utilized to estimate the fraction of fuel consumed in power generation, and this assumption is applied at the resolution of the state. The analysis does not normalize water consumption over the functional unit of electricity generated because data were not available at the resolution of watersheds; however, with improved datasets, more complete assessments can be undertaken that assess impacts for each 
watershed per unit electricity generated. The spatially-resolved inventory may be considered a first step towards better coupling of spatially-explicit inventories and impact assessments in LCA at ecologically-relevant scales.

\section{Theory}

It has been argued that LCA does not maintain enough of a focus on the consumptive use of water because the explicit focus of spatial differentiation has been on the impact assessment stage of LCA [20]. The response to this argument is that water consumption can be included within the inventory analysis stage of LCA methodology [26]. In fact, Pfister et al. [26] specifically identified the potential for the inventory stage of LCA to include the location of water consumption; however, the present authors have yet to identify a comprehensive inventory for water consumption for power generation that is spatially disaggregated and presented at an ecologically-relevant resolution such as watersheds. We focus the efforts of this study to present a way in which such spatially differentiated inventories can be compiled.

LCA necessitates the use of a functional unit, where the environmental burden is divided by an output; for example, water use is calculated per functional unit of generated electricity (gallons per Megawatt-hour (MWh)) [52]. For spatially-resolved LCAs, we suggest that functional units may be selected either as spatial units of analysis (e.g. water consumption per watershed) or as products (e.g. water consumption per unit of electricity generated). If the latter, the impact assessment may be most useful if undertaken before relating the data to the functional unit to characterize the watershed-scale impacts per functional unit (which is atypical for LCA); for example, water scarcity may be more accurately characterized with the evaluation of water 
budgets for each individual watershed. Impacts to each watershed could then be presented per unit of electricity produced, enabling researchers to identify regions which have relatively high or low impacts.

A new boundary problem is thus presented when selecting the functional unit for spatiallydifferentiated LCA: spatial boundaries may not match the boundaries of the LCA. In the case of our analysis, the spatial boundaries are the state of Pennsylvania with the unit of analysis being the watershed; however, natural gas may be exported and used out of state or even internationally. Ideally, system boundaries for LCA should be traced back to include all raw materials from derived from the environment in the process and the associated impacts to the environment (e.g. emissions or resource use) [51, 53].

The two approaches that we use to develop inventories disaggregated at the watershed-scale are: (1) the total water consumed by fuel consumption and power generation in the coal-to-gas transition of the power sector in Pennsylvania from 2009-2012 (Figure 1a), and (2) the end product water consumption, which includes the natural gas and coal-fired electricity generation in the state in addition to the fraction of fuel extracted that is consumed by this electricity generation from 2009-2012 (Figure 1b). The system boundaries for the former includes the water consumption for each fuel extraction site and power plant in each watershed. The system boundaries for the latter include the power generation and the fuel consumed by power generation in the state, but results remain spatially differentiated at the scale of watersheds (Figure 1). The former case suggests the watershed is the functional unit whereas the latter captures only the water consumed in the state to generate electricity (including fuel extraction 
and power generation) but does not normalize over a functional unit (e.g. per MWh). With more comprehensive datasets about spatiotemporal flows of energy products at the watershed-scale, impact assessments could include normalization of the impacts over the functional unit for end product inventory analyses for each individual watershed. Regionalization in LCA has primarily focused on impacts (e.g. to water scarcity); therefore, results for the latter case may be useful for developing spatially resolved inventories where the impact assessment stage of LCA can account for spatial differentiation associated with the location of consumption with results normalized per unit electricity generated.

[Figures 1 (a) and (b)]

To the best of the author's knowledge, methods to account for water scarcity in life cycle impact assessment do not (at present) reflect these differences in water consumption inventories at the watershed-scale. The estimation of total water consumption associated with the coal to gas transition allows analysts to get a more comprehensive picture of the impact of technology transitions on actual watersheds while making clear the spatial assumptions that are needed and the data limitations for the end product estimates. Accordingly, spatially-resolved inventories complement the findings from LCAs of electricity generation, where technological comparisons of the life cycle water consumption by coal- and natural gas-fired electricity generation can inform policy alongside the watershed-level implications of the related energy transitions.

While not all natural gas extracted in Pennsylvania is used for electricity generation, all shale gas that has been extracted in Pennsylvania consumes water during the hydraulic fracturing process, in turn directly influencing water budgets of particular watersheds. Natural gas is consumed by a 
number of end uses in Pennsylvania, including commercial, residential, industrial, electric power, and vehicular (Figure 2). The only end use for natural gas that is considered in our analysis is power generation. The reasons for this are that: (a) power generation is the largest growing consumer of natural gas in Pennsylvania; (b) the sector has seen large changes in the region over the time period examined in this study; and (c) the sector has heavily localized water consumption patterns over the life of the plant (when compared to wells, for example, which are more acute temporally). The data suggest new consumption is associated with growth in natural gas-fired power generation (Figure 2). With more data on the spatial flows of energy products, this approach may be further developed in LCA methodology to include different end uses, where results would be normalized over a functional unit (e.g. in the case of electricity, a MWh).

[Figure 2]

\section{Results}

\subsection{Total water consumption of the coal-to-gas transition (2009-2012)}

The total water consumption for the power and fuel extraction sectors was found to increase from 308 to 316 million $\mathrm{m}^{3}$ from 2009 to 2012 (82 Bgal to 84 Bgal), representing an increase of 8 million $\mathrm{m}^{3}$ (2 Bgal) [1]. Changes in the sign (increase or decrease) and the magnitude of water consumption fluctuated widely among watersheds (Figure 3a). For example, the largest reduction in annual water consumption between 2009 and 2012 was 14 million $\mathrm{m}^{3}$ (0.4 Bgal) in the Conemaugh Watershed (HUC 5010007, details on watershed delineation in the Supplementary Material). The largest increase in annual water consumption over the same period was 7 million $\mathrm{m}^{3}$ (0.2 Bgal) in the Upper Susquehanna-Tunkhannock Watershed (HUC 2050106). 
Watersheds experiencing reductions in water consumption generated less coal-fired power, compensating for any increases in water consumption due to increased shale gas extraction or natural gas-fired power. In contrast, nearly all watersheds with the highest growth in water consumption experienced increases in shale gas extraction. Watersheds in the southeast corner of Pennsylvania were the exception, where the growth in natural gas-fired power increased overall consumption (Figure 3).

\section{[Figure 3]}

Coal-fired power was responsible for the majority of water consumption in the state; however, its contribution to the total amount water consumed decreased from $86 \%$ to $73 \%$ from 2009 to 2012 as a result of the reduced generation. Annual water consumption for shale gas extraction increased from $1 \%$ to $9 \%$ over the same period, while water consumption for natural gas-fired power increased from $8 \%$ to $13 \%$ of total water consumed by the four uses investigated (shale gas extraction, coal extraction, natural gas power generation and coal power generation). The estimated amount of water consumed in coal extraction remained constant at $5 \%$ of total annual water consumption over the time period. While data used to make this estimate were limited and do not reflect possible seasonal variations in water consumption for coal extraction, results provide an order-of-magnitude understanding of how the water consumed by coal mining compares to the other activities (other fossil fuel extraction and different types of fossil power generation). 


\subsection{End-product water consumption estimates (2009-2012)}

End product water consumption (where the fuel assessment is limited to the fuel consumed by the power sector) decreased from 305 to 289 million $\mathrm{m}^{3}$ from 2009 to 2012 (81 Bgal to 76 Bgal), representing a reduction of 16 million $\mathrm{m}^{3}$ (4 Bgal) (Figure $3 \mathrm{~b}$ ). Similar spatial variability to the first approach were apparent across watersheds, with variation in volume and sign of water consumption. Coal-fired power generation was responsible for the majority of water consumption, although its contribution to the total amount of water consumed in the aforementioned four industrial activities decreased from $87 \%$ in 2009 to $80 \%$ in 2012 as a result of less coal-fired generation. Water consumption for hydraulic fracturing to extract shale gas was less prominent for this case when compared to the total water consumed, increasing from $1 \%$ to only $2 \%$ of annual water consumption. Natural gas-fired electricity generation experienced similar increases (from $8 \%$ to $14 \%$ ). The amount of water consumed in coal extraction remained constant throughout the period at $4 \%$ of annual water consumption for extraction and power generation. Tabular results are available in the Supplementary Material for both approaches.

\section{Discussion}

The inventory developed here is an initial step towards spatially-resolved LCA of power generation, providing insight into the spatial variability of the water consumed by technology transition at the scale of watersheds. Analyses of power generation have commenced to incorporate spatiotemporal factors [21-23]; however, these evolving methods have yet to be reflected in LCA. To date, LCAs have not captured watershed-level changes in water consumption at temporal scales that can affect actual investment decisions where water resources may be limited environmentally or through policy. More comprehensive datasets describing the 
spatial flows of products (e.g. the precise location and use of natural gas extracted and combusted for power generation in Pennsylvania) would further enable a more representative picture of water consumption across watersheds over the life cycle of products.

The implications of spatially explicit inventories for LCA methodology may become more pronounced in the future. Existing LCA results correctly show that natural gas-fired power consumes less water than coal-fired power on the basis of a functional unit (i.e. per MWh). Yet, changes in water consumption at the watershed (HUC8) scale are variable and relevant for the deployment of new energy technologies. We suggest that watershed-level inventories of the water consumed by the coal-to-gas transition such as those presented here can serve as useful complements to existing LCAs of electricity generation until more extensive, spatially-resolved LCA methodology has been further developed. The results are meant to add clarity on the decisions that must be addressed in advancing spatial LCA and more generally for policy-makers to interpret life cycle results when decisions may be influenced by the changing patterns of water consumption associated with technological transitions.

Results indicate that changes in water consumption for specific watersheds from the coal-to-gas transition depend on currently existing (and new) infrastructure and the underlying geology; in this case, coal mines, natural gas wells, and power plants. Watersheds experiencing the retirement of coal-fired power plants are most likely to experience net water reductions, whereas those watersheds experiencing growth in shale gas development without reductions in coal power will experience net increases in water consumption. Using a spatially-resolved inventory, analysts can examine aggregate changes in life cycle water consumption associated with 
technology change in addition to the changes experienced by specific watersheds over shorter time horizons where water availability may be constrained by weather and hydrological factors. Limits to withdrawals at the watershed-level may be imposed by local decision-makers due to the combination of factors affecting water demand and availability, impacting projects being developed in that particular watershed. Results for monthly water consumption changes for each watershed in Pennsylvania for the coal to gas transition from 2009-2012 can be found using our online tool: https://nicholasinstitute.duke.edu/hydraulic-fracturing/. The approach we employed to develop the inventory presented here addresses a limitation in LCA: water consumption has yet to be examined using spatially-resolved life cycle methods at the scale of watersheds and months. To understand actual life cycle water impacts, the inventories and impacts have to be connected. In order to do so, LCA methods will require expansion to analyze the water consumption both in spatial and functional units.

\section{Conclusions}

We estimate the water implications of the 26-fold increase in unconventional natural gas extracted in Pennsylvania between 2009 and 2012 and the subsequent effects of water consumption due to related changes in the composition of the power sector. Results suggest that the overall change in water consumption associated with fuel extraction and power generation increased by $2.6 \%$ and that the effects are heterogeneous across watersheds. We explore the assumptions needed to assemble the inventories required for spatially-resolved LCA of electricity generation. When estimating the water consumed by power generation and the portion of the fuel used to generate electricity, the overall water consumption completely reversed with a net decrease of $5.3 \%$. Similar reversals of results occurred in some watersheds, while changes in 
water consumption became less pronounced in others. Previous life cycle and technology assessment estimates for water consumption, such as those reported in Section 1.1, do not capture the variability in water consumption across watersheds. In undertaking this analysis, we have not only taken a step towards the development of spatially-resolved life cycle inventories but also presented a useful accounting method for policy-makers and investors to better understand the changing spatial patterns of the water consumed during energy and technology transitions. Our analysis, however, only captured fuel extraction and electricity generation. Future research may include more detailed spatiotemporal water consumption inventories using a similar approach but with more life cycle stages captured within system boundaries.

While our analysis contributes towards the development of spatially- and temporally-resolved LCA, limitations in the data must be noted. Estimating the water consumed by life cycle stages of electricity at the watershed scale required making state-level assumptions about the location of the natural gas extracted for use in electricity. While we make this assumptions explicit and test the robustness of the results to different assumptions, future data collection could strengthen the basis for the assumptions. Comprehensive spatiotemporal datasets describing the flows of energy products would support more representative spatial allocation of the water consumed by specific products. Knowing the quantity of water consumed at each site, from which specific streams the water is extracted, the timing of extraction, pumping rates, etc. for each sector would enhance decision-making capabilities and determinations of when and where direct limits to water withdrawals may be required. Data describing water consumed by coal mining and washing, for instance, is outdated and not available at the state or mine level $[48,55]$. While not considered here, recent data have yet to be compiled to verify the relative well-level water 
consumption of conventional gas with analyses often relying on outdated data [48], emphasizing the need to improve data on water consumed by fuel extraction. Another example is water consumption data for reclamation, where data on water required for re-vegetation of areas that were previously coal mines are lacking. Future research by academics, government, and industry should focus on improving datasets for improving spatially differentiated assessments of fuel extraction and power generation technologies. Finally, the goal of our research contribution necessitates a descriptive analysis of water consumption. While out of the scope of this paper, such datasets may be applied within other fields in the future, such as econometrics, to answer questions regarding how institutional changes may contribute to changes in water consumption.

Our analysis captures only electricity generation as the end production. For the case of Pennsylvania, a significant portion of the natural gas produced is not consumed in power generation within the state. As a result, it would be useful to expand this approach to account for the water consumption patterns of other natural gas end products if more spatiotemporally resolved data on such uses became available. Scholars could thus create an even more holistic picture of local water consumption from expanding shale gas development. Improving datasets will move the field of LCA closer to the development of more sophisticated, spatially differentiated results; for example, through building an economy-wide spatially explicit inputoutput LCA model. With new methods and spatially-resolved inventories, LCA can move towards capturing the spatially heterogeneous water consumption patterns necessary to understand the water implications of technological change at spatial scales relevant to decisionmakers. 


\section{Acknowledgements}

This research did not receive any specific grant from funding agencies in the public, commercial, or not-for-profit sectors. The authors thank John Rogers of the Union of Concerned Scientists (UCS) for useful conversations and suggestions in the early phases of this project and for providing access to the UCS database on cooling technologies in U.S. power plants. The Energy Information Administration provided additional detail about the power plant data in its reports. An earlier version of this paper was published as a working paper through the Nicholas Institute at Duke University and the Harvard Belfer Center for Science and International Affairs.

\section{References}

[1] Patterson LA, Jordaan SM, Anadon LD. A Spatiotemporal Exploration of Water Consumption Changes Resulting from the Coal-to-Gas Transition in Pennsylvania. Nicholas Institute for Environmental Policy Solutions, Duke University; Belfer Center for Science and International Affairs, Harvard Kennedy School 2016.

[2] Reap J, Roman F, Duncan S, Bras B. A survey of unresolved problems in life cycle assessment. The International Journal of Life Cycle Assessment 2008;13(5):374-388.

[3] Ekvall T, Finnveden G. Allocation in ISO 14041 - A Critical Review. Journal of Cleaner Production 2001;9(3):197-208.

[4] Jordaan SM, Diaz Anadon L, Mielke E, Schrag DP. Regional water implications of reducing oil imports with liquid transportation fuel alternatives in the United States. Environmental Science \& Technology 2013;47(21):11976-11984.

[5] Grubert EA, Beach FC, Webber ME. Can switching fuels save water? A life cycle quantification of freshwater consumption for Texas coal-and natural gas-fired electricity. Environmental Research Letters 2012;7(4):045801.

[6] Clark CE, Horner RM, Harto CB. Life cycle water consumption for shale gas and conventional natural gas. Environmental Science \& Technology 2013;47(20):11829-11836.

[7] Meldrum J, Nettles-Anderson S, Heath G, Macknick J. Life cycle water use for electricity generation: a review and harmonization of literature estimates. Environmental Research Letters 2013;8(1):015031. 
[8] Yang Y. Toward a more accurate regionalized life cycle inventory. Journal of Cleaner Production 2016;112:308-315.

[9] International Organization for Standardization (ISO). 14040 International standard:

Environmental Management-Life Cycle Assessment-Principles and Framework, International Organisation for Standardization, Geneva, Switzerland. 2006.

[10] Pfister S, Saner D, Koehler A. The environmental relevance of freshwater consumption in global power production. The International Journal of Life Cycle Assessment 2011;16(6):580591.

[11] Quinteiro P, Ridoutt BG, Arroja L, Dias AC. Identification of methodological challenges remaining in the assessment of a water scarcity footprint: a review. The International Journal of Life Cycle Assessment 2017:1-17.

[12] Mutel CL, Pfister S, Hellweg S. GIS-based regionalized life cycle assessment: how big is small enough? Methodology and case study of electricity generation. Environmental Science \& Technology 2011;46(2):1096-1103.

[13] Scown CD, Horvath A, McKone TE. Water footprint of US transportation fuels. Environmental Science \& Technology 2011;45(11):2541-2553.

[14] Berger M, Finkbeiner M. Water footprinting: How to address water use in life cycle assessment? Sustainability 2010;2(4):919-944.

[15] Hellweg S, Mila i Canals L. Emerging approaches, challenges and opportunities in life cycle assessment. Science 2014 Jun 6;344(6188):1109-1113.

[16] Şengül H, Bayrak F, Köksal MA, Ünver B. A cradle to gate life cycle assessment of Turkish lignite used for electricity generation with site-specific data. Journal of Cleaner Production 2016;129:478-490.

[17] Siddiqui O, Dincer I. Comparative assessment of the environmental impacts of nuclear, wind and hydro-electric power plants in Ontario: A life cycle assessment. Journal of Cleaner Production 2017;164:848-860.

[18] Tessum CW, Marshall JD, Hill JD. A spatially and temporally explicit life cycle inventory of air pollutants from gasoline and ethanol in the United States. Environmental science \& technology 2012;46(20):11408-11417.

[19] Koehler A. Water use in LCA: managing the planet's freshwater resources. International Journal of Life Cycle Assessment 2008;13(6):451-455.

[20] Hoekstra AY. A critique on the water-scarcity weighted water footprint in LCA. Ecological Indicators 2016;66:564-573. 
[21] Peck JJ, Smith AD. Quantification and regional comparison of water use for power generation: A California ISO case study. Energy Reports 2017;3:22-28.

[22] Peer RA, Garrison JB, Timms CP, Sanders KT. Spatially and temporally resolved analysis of environmental trade-offs in electricity generation. Environmental science \& technology 2016;50(8):4537-4545.

[23] Peer RA, Sanders KT. The water consequences of a transitioning US power sector. Applied Energy 2017;210:613-622.

[24] Jiang M, Hendrickson CT, VanBriesen JM. Life cycle water consumption and wastewater generation impacts of a Marcellus shale gas well. Environmental Science \& Technology 2014;48(3):1911-1920.

[25] Chang Y, Huang R, Ries RJ, Masanet E. Life-cycle comparison of greenhouse gas emissions and water consumption for coal and shale gas fired power generation in China. Energy 2015;86:335-343.

[26] Pfister S, Boulay A, Berger M, Hadjikakou M, Motoshita M, Hess T, et al. Understanding the LCA and ISO water footprint: A response to Hoekstra (2016)"A critique on the waterscarcity weighted water footprint in LCA". Ecological Indicators 2017;72:352-359.

[27] Wigley TM. Coal to gas: the influence of methane leakage. Climatic Change 2011;108(3):601.

[28] Kondash A, Vengosh A. Water footprint of hydraulic fracturing. Environmental Science \& Technology Letters 2015;2(10):276-280.

[29] Mielke E, Anadon LD, Narayanamurti V. Water consumption of energy resource extraction, processing, and conversion. Belfer Center for Science and International Affairs 2010.

[30] Jordaan SM, Diaz-Anadon L, Schrag D. Temporal Aspects of Water Use in Shale Gas Development: Implications for LCA. Session on Fossil Fuels, Life Cycle Analysis (LCA) XI. Chicago, MI, United States. October 4-6, 2011. American Center for Life Cycle Assessment 2011.

[31] Vengosh A, Jackson RB, Warner N, Darrah TH, Kondash A. A critical review of the risks to water resources from unconventional shale gas development and hydraulic fracturing in the United States. Environmental Science \& Technology 2014;48(15):8334-8348.

[32] Nicot J, Scanlon BR, Reedy RC, Costley RA. Source and fate of hydraulic fracturing water in the Barnett Shale: a historical perspective. Environmental Science \& Technology 2014;48(4):2464-2471.

[33] Nicot J, Scanlon BR. Water use for shale-gas production in Texas, US. Environmental Science \& Technology 2012;46(6):3580-3586. 
[34] NYSDEC. Best Technology Available (BTA) for Cooling Water Intake Structures. New York State Department of Environmental Conservation (NYDEC) 2011.

[35] California State Land Commision. Resolution by the California State Lands Commission Regarding Once-Through Cooling in California Power Plants. 2006; Available at:

http://www.energy.ca.gov/siting/documents/2006-04-13_SLC_PROPOSED_COOLING.PDF. Accessed August 10, 2017.

[36] Macknick J, Newmark R, Heath G, Hallett KC. Operational water consumption and withdrawal factors for electricity generating technologies: a review of existing literature. Environmental Research Letters 2012;7(4):045802.

[37] Detrow S. SRBC Suspends Water Withdrawals in 5 Counties. 2012; Available at: https://stateimpact.npr.org/pennsylvania/2012/04/18/srbc-suspends-water-withdrawal-in-5counties/. Accessed August 10, 2017.

[38] Sovacool BK, Sovacool KE. Identifying future electricity-water tradeoffs in the United States. Energy Policy 2009;37(7):2763-2773.

[39] Energy Information Administration (EIA). Table CT8. Electric Power Sector Consumption Estimates, 1960-2015, Pennsylvania. 2016; Available at:

https://www.eia.gov/state/seds/data.php?incfile=/state/seds/sep_use/eu/use eu pa.html\&sid=PA. Accessed August 10, 2017.

[40] Pennsylvania Department of Environmental Protection. 2015 Oil and Gas Annual Report. 2015; Available at: http://www.elibrary.dep.state.pa.us/dsweb/Get/Document-113887/8000-REDEP4621.pdf. Accessed August 10, 2017.

[41] Macknick J, Newmark R, Heath G, Hallett K. Review of Operational Water Consumption and Withdrawal Factors for Electricity Generating Technologies. National Renewable Energy Laboratory (NREL), Golden, CO 2011;NREL/TP-6A20-50900.

[42] Susquehanna River Basin Commission. Natural Gas Well Development in the Susquehanna River Basin. 2013; Available at:

http://www.srbc.net/programs/docs/naturalgasinfosheetjan2013.pdf;. Accessed August 10, 2017.

[43] Sullivan K, Cyterski M, Knightes C, Price K, Kim K, Prieto L, et al. Case Study Analysis of the Impacts of Water Acquisition for Hydraulic Fracturing on Local Water Availability.

EPA/600/R-14/179. 2015.

[44] Fracfocus. Find a well. 2014; Available at: http://fracfocus.org/find-well-by-state. Accessed August 10, 2017.

[45] Drilling Info (DI). Desktop (2013) Version 6.2.1.0. 2015; Available at:

info.drillinginfo.com. Accessed December 12, 2016. 
[46] Pennsylvania Department of Environmental Protection. PA DEP Oil \& Gas Reporting Website. 2014; Available at:

http://www.dep.pa.gov/DataandTools/Reports/Oil\%20and\%20Gas\%20reports/Pages/default.asp x. Accessed August 10, 2017.

[47] Mine Safety and Health Administration. Mines Data Set. 2015; Available at: https://arlweb.msha.gov/OpenGovernmentData/OGIMSHA.asp. Accessed August 10, 2017.

[48] Gleick PH. Water and Energy. Annual Review of Energy and the Environment 1994;19(1):267-299.

[49] Energy Information Administration (EIA). EIA 860: existing and planned generators and associated environmental equipment at electric power plants with 1 megawatt or greater of combined nameplate capacity. Form EIA-860 detailed data. 2013; Available at: https://www.eia.gov/electricity/data/eia860/. Accessed August 25, 2015.

[50] Energy Information Administration (EIA). Net Generation by State by Type of Producer by Energy Source. EIA-906, EIA-920, and EIA-923. 2013; Available at: http://www.eia.gov/electricity/data/state/. Accessed August 25, 2016.

[51] Li T, Zhang H, Liu Z, Ke Q, Alting L. A system boundary identification method for life cycle assessment. The International Journal of Life Cycle Assessment 2014;19(3):646-660.

[52] Rebitzer G, Ekvall T, Frischknecht R, Hunkeler D, Norris G, Rydberg T, et al. Life cycle assessment: Part 1: Framework, goal and scope definition, inventory analysis, and applications. Environment International 2004;30(5):701-720.

[53] Finnveden G, Hauschild MZ, Ekvall T, Guine J, Heijungs R, Hellweg S, et al. Recent developments in life cycle assessment. Journal of Environmental Management 2009;91(1):1-21.

[54] Energy Information Administration (EIA). Pennsylvania Natural Gas Consumption by End Use. 2017; Available at: https://www.eia.gov/dnav/ng/ng_cons_sum_dcu_SPA_m.htm. Accessed July $31,2017$.

[55] Vidal de la Blache, P., Kourlis S. Water and Energy Nexus: A Literature Review. Water in the West A joint program of Stanford Woods Institute for the Environment and Bill Lane Center for the American West 2013. 